\title{
Mast cell heterogeneity and anti-inflammatory annexin A1 expression in leprosy skin lesions
}

\author{
Maurício B. Costa ${ }^{\mathrm{a}, 1}$, Kallyne K.O. Mimura ${ }^{\mathrm{b}, 1}$, Aline A. Freitas ${ }^{\mathrm{a}}$, Emerith M. Hungria ${ }^{\mathrm{a}}$, \\ Ana Lúcia O.M. Sousa ${ }^{\mathrm{a}}$, Sonia M. Oliani ${ }^{\mathrm{b}}$, Mariane M.A. Stefani ${ }^{\mathrm{a}, *}$ \\ a Tropical Pathology and Public Health Institute, Federal University of Goiás, Goiânia, Brazil \\ ${ }^{\mathrm{b}}$ Department of Biology, Instituto de Biociências, Letras e Ciências Exatas, Sao Paulo State University, UNESP, São José do Rio Preto, SP, Brazil
}

\section{A R T I C L E I N F O}

\section{Keywords:}

Mast cell

Annexin A1

Tryptase

Chymase

Leprosy

Skin diseases

\begin{abstract}
A B S T R A C T
Mast cells (MCs) have important immunoregulatory roles in skin inflammation. Annexin A1 (ANXA1) is an endogenous anti-inflammatory protein that can be expressed by mast cells, neutrophils, eosinophils, monocytes, epithelial and T cells. This study investigated MCs heterogeneity and ANXA1 expression in human dermatoses with special emphasis in leprosy. Sixty one skin biopsies from 2 groups were investigated: 40 newly diagnosed untreated leprosy patients (18 reaction-free, 11 type 1 reaction/T1R, 11 type 2 reaction/T2R); 21 patients with other dermatoses. Tryptase/try + and chymase/chy + phenotypic markers and toluidine blue stained intact/ degranulated MC counts $/ \mathrm{mm}^{2}$ were evaluated. Try ${ }^{+} / \mathrm{chy}^{+} \mathrm{MCs}$ and ANXA1 were identified by streptavidinbiotin-peroxidase immunostaining and density was reported. In leprosy, degranulated MCs outnumbered intact ones regardless of the leprosy form (from tuberculoid/TT to lepromatous/LL), leprosy reactions (reactional/ reaction-free) and type of reaction (T1R/T2R). Compared to other dermatoses, leprosy skin lesions showed lower numbers of degranulated and intact MCs. Try ${ }^{+}$MCs outnumbered chy ${ }^{+}$in leprosy lesions (reaction-free/reactional, particularly in T2R), but not in other dermatoses. Compared to other dermatoses, ANXA1 expression, which is also expressed in mast cells, was higher in the epidermis of leprosy skin lesions, independently of reactional episode. In leprosy, higher MC degranulation and differential expression of try ${ }^{+} /$chy $^{+}$subsets independent of leprosy type and reaction suggest that the Mycobacterium leprae infection itself dictates the inflammatory MCs activation in skin lesions. Higher expression of ANXA1 in leprosy suggests its potential antiinflammatory role to maintain homeostasis preventing tissue and nerve damage.
\end{abstract}

\section{Introduction}

Mast cells (MCs) form a component of the immune system that play an important role in host defense [1]. MCs represent one of the most versatile cells in the body and in the skin due to their ubiquitous distribution and the plethora of biologically active molecules they produce [2]. Besides allergic responses, MCs play a much broader role in cutaneous inflammatory and non-inflammatory diseases promoting or suppressing inflammation. In normal skin, mast cells accumulate in the upper dermal region, around vessels, nerves and appendages [3], and are abundant in organs exposed to the environment like the respiratory and gastrointestinal tracts and the skin [4,5]. The location of mast cells in the dermal layer of the skin allows a quick response to injury [6].

The involvement of MCs and their serine proteases in the physiology and pathology of inflammation identifies these immune cells and their granule constituents as intriguing targets for therapy [7]. Neutral granule proteases expressed by human MC represent their best phenotypic markers allowing the differentiation of connective tissue MC that contain tryptase (try ${ }^{+} \mathrm{MC}$ ), chymase (chy ${ }^{+} \mathrm{MC}$ ) and tryptase/chymase (try $^{+} \mathrm{chy}^{+} \mathrm{MC}$ ). Mucosal MC contains only tryptase (try ${ }^{+} \mathrm{MC}$ ) $[1,8-10]$. Besides pre-formed mediators as proteases, histamine, heparin proteoglycan, newly-synthesized mediators can be secreted upon activation, including antimicrobial peptides (cathelicidins) [11]. Mast cells have been implicated in the immune response to pathogens in various tissues contributing to the clearance of Escherichia coli, Klebsiella pneumoniae and Mycoplasma pneumoniae [12,13]. MCs participate in cutaneous immunity of leishmaniasis, in Escherichia coli and Haemaphysalis longicornis infections and in Pseudomonas aeruginosa infection [14]. Mast cells can also act as multifunctional inflammatory cells in a diverse set of immunological and physiological conditions regulating

\footnotetext{
Abbreviations: MC, Mast cells; ANXA1, Annexin A1; T1R, type 1 reaction; T2R, type 2 reaction; Try +: Tryptase, Chy +: Chymase

* Corresponding author. Tropical Pathology and Public Health Institute, Federal University of Goiás, Rua 235 s/n Setor Universitário, $74605-050$, Goiânia, Goiás, Brazil.

E-mail addresses: mmastefani@gmail.com, mariane.stefani@pq.cnpq.br (M.M.A. Stefani).

${ }^{1}$ Both authors contributed equally to this research.
} 
cutaneous wound healing after trauma and neo-angiogenesis in malignancies [15-17]. MCs undergo slow and partial degranulation after activation but other mechanisms as exosome secretion and selective degranulation-independent secretion have been described [11,18,19].

Annexin A1 (ANXA1) is an endogenous anti-inflammatory molecule expressed by mast cells, neutrophils, eosinophils, monocytes, epithelial $\mathrm{T}$ cells that can modulate biological events in cancer progression and metastasis and in various models of inflammatory and autoimmune diseases [20-26]. ANXA1 is a member of the annexin superfamily of calcium- and phospholipid-binding proteins that participates in chronic inflammation, leukocyte migration, tissue growth and apoptosis $[27,28]$. ANXA1 has been shown to be very effective in limiting inflammation and is expressed in different immune cells recruited during infectious processes, particularly mast cells and neutrophils [20,29].

Leprosy is a dermato-neurological granulomatous disease caused by Mycobacterium leprae that represents an important public health problem in many endemic countries including India and Brazil [29]. Leprosy shows a wide spectrum of clinical manifestations which depend on the host immune response ranging from few localized skin lesions in paucibacillary (PB) disease with Th1 type cell mediated immunity, to disseminated multibacillary (MB) disease characterized by Th2 type humoral immunity. During the chronic course of leprosy, some patients can develop acute immune inflammatory episodes known as type 1 and type 2 reactions (T1R, T2R) that can lead to irreversible nerve damage and consequent deformities [30]. Leprosy skin lesions contain all the cells that are present in normal skin including MCs, and also cells that migrate from the peripheral blood as a consequence of the infectiousgranulomatous response. The data about MCs in leprosy skin lesions are controversial however the majority of studies indicate increased number in lepromatous lesions [31-35]. This study investigated MCs activation, heterogeneity and ANXA1 expression in leprosy skin lesions including T1R and T2R.

\section{Material and methods}

\subsection{Study groups}

This study included 61 skin biopsies from two study groups: leprosy and other skin diseases (named "other dermatoses" group). Forty newly diagnosed, untreated leprosy patients were recruited at a main regional public health center for leprosy diagnosis and treatment (Centro de Referência em Diagnóstico e Terapêutica/CRDT in Goiânia, Goiás, Central Western Brazil) a highly endemic area for leprosy. Patients had complete dermato-neurological examination by one physician with expertise in leprosy diagnosis (ALOMS). Leprosy patients were classified according to Ridley \& Jopling criteria considering clinical, bacilloscopic index (BI) and histopathologic findings as tuberculoid/TT, borderline-tuberculoid/BT, borderline-borderline/BB, borderline lepromatous/BL, lepromatous/LL [36]. Leprosy group comprised 14 paucibacillary patients (TT, BT, all of them BI negative) and 26 multibacillary patients (BT, BL, LL, all of them BI positive). In the leprosy group, 18 were reaction-free and 22 had leprosy reactions (11 type 1 reaction and 11 type 2 reactions).

Patients with other skin diseases $(n=21)$ recruited at the same reference center were diagnosed based on histopathology: nonspecific chronic inflammatory process $(n=3)$, chromomycosis $(n=1)$, cutaneous leishmaniasis $(n=3)$, paracoccidioidomycosis $(n=3)$, herpes (1), lichen planus (2) granuloma annulare (3), scleroderma (2) vitiligo (3).

Exclusion criteria were: co-morbidities (AIDS, tuberculosis, diabetes mellitus), age under 18 years and pregnant women. Main features of study participants (Table 1) indicate predominance of males among leprosy patients while females predominated among patients with other dermatoses. Age of participants (leprosy, other dermatoses) was similar $(\mathrm{p}=0.730)$.
Table 1

Main features of study groups.

\begin{tabular}{lll}
\hline Group & Gender $(\mathrm{M} / \mathrm{F})$ & Age (years) (median, range) \\
\hline Leprosy $(\mathrm{n}=40)$ & $29 / 11$ & $50(20-95)$ \\
$\mathrm{PB}^{\mathrm{a}}(\mathrm{n}=14)$ & $9 / 5$ & $52(30-95)$ \\
$\mathrm{MB}^{\mathrm{b}}(\mathrm{n}=26)$ & $20 / 6$ & $49(20-66)$ \\
$\mathrm{T} 1 \mathrm{R}(\mathrm{n}=11)$ & $7 / 4$ & $50(33-66)$ \\
T2R $(\mathrm{n}=11)$ & $8 / 3$ & $48(20-95)$ \\
Other dermatoses $(\mathrm{n}=21)$ & $10 / 11$ & $58(20-79)$ \\
\hline
\end{tabular}

$\mathrm{PB}^{\mathrm{a}}$ : paucibacillary leprosy (10 TT patients, $4 \mathrm{BT}$ ); $\mathrm{MB}^{\mathrm{b}}$ : multibacillary leprosy (6 BT, 15 LL, 5 BL); T1R: type 1 reaction; T2R: type 2 reaction; M: Male; F: Female.

\subsection{Histopathological analysis}

Skin biopsies $(4 \mathrm{~mm})$ were taken from the edges of well-characterized, infiltrated lesions ( $24 \mathrm{~h}$ fixation, $4 \%$ neutral buffered paraformaldehyde). For leprosy, 3-4 $4 \mathrm{~m}$ sections were stained by Hematoxylin-Eosin (HE) and by Fite-Faraco for bacilli detection and used for the Ridley \& Jopling classification.

Toluidine blue stained sections $(0.5 \%$ alcohol $)$ were used for the quantitative analysis of intact and degranulated MCs. Intact mast cells were identified by metachromatic purple stained granules in the cytoplasm due to sulfated acid mucopolyssaccharides; degranulated mast cells were defined by weak purple intra cytoplasmatic staining and visualization of staining outside the cell limits [37]. MCs were identified (ZEISS-AXIOSKOP 2, ZEISS, Jena, Germany), photographic digital images were obtained $\left(1.0 \mathrm{~mm}^{2}, 27\right.$ fields/section; AXIOVISION, 63X, ZEISS, Jena, Germany) and analyzed by two independent experts (KKOM, MBC) blinded to the participants' groups giving comparable results $(\mathrm{p}=0.63)$. For the intralesional count, the entire area of the skin lesion was scanned; immuno-positive cell and the number of fields were recorded. The perilesional count included the number of positive cells in fields along the interface between the lesion/neighborhood.

\subsection{Immunohistochemical analysis}

\subsubsection{Tryptase and chymase}

Tryptase and chymase positive MCs were detected by streptavidinbiotin-peroxidase immunostaining $(\mathrm{n}=61)$ in deparafinized, rehydrated biopsies with antigen retrieval induced by heat (citrate buffer, $\mathrm{pH} 6,96^{\circ} \mathrm{C}, 20 \mathrm{~min}$ ), endogenous peroxidase blocked (3\% hydrogen peroxidase, $30 \mathrm{~min}$ ). Primary antibody (mouse monoclonal anti-human tryptase, AA1; 1:1000, Dako, Glostrup, Denmark or rabbit monoclonal anti-mast cell chymase-C-terminal, CC1, 1:100; Abcam, Cambridge, UK) was incubated $\left(16 \mathrm{~h}, 4^{\circ} \mathrm{C}\right)$. Biotinylated secondary antibody and peroxidase-streptavidin complex (Invitrogen, Carlsbad, USA) were added and reactions revealed (3,3-diaminobenzidine, DAB, Invitrogen, Carlsbad, USA). Sections were counterstained (Harris hematoxylin); negative controls did not include the primary antibody; positive controls were sections of normal small intestine mucosa, which are rich in MCs and were used to validate immunostaining techniques.

\subsubsection{Annexin A1 protein}

Immunohistochemistry was used to detect the expression of ANXA1 ( $n=25,5$ /group): other dermatoses, MB leprosy skin lesions, PB leprosy skin lesions, leprosy type 1 reaction/T1R and type 2 reaction/ T2R. Sections were incubated (citrate buffer $\mathrm{pH}$ 6.0), the endogenous peroxide activity was blocked, sections were incubated with the primary rabbit polyclonal antibodies anti-ANXA1 (1:2000; Zymed Laboratories, Cambridge, UK; overnight, $4^{\circ} \mathrm{C}$, in $1 \%$ BSA). After washing, sections were incubated with a secondary biotinylated antibody (Invitrogen, Carlsbad, USA). Positive staining was detected using a peroxidase conjugated streptavidin complex and color developed using DAB substrate (Invitrogen, Carlsbad, USA). The sections were 


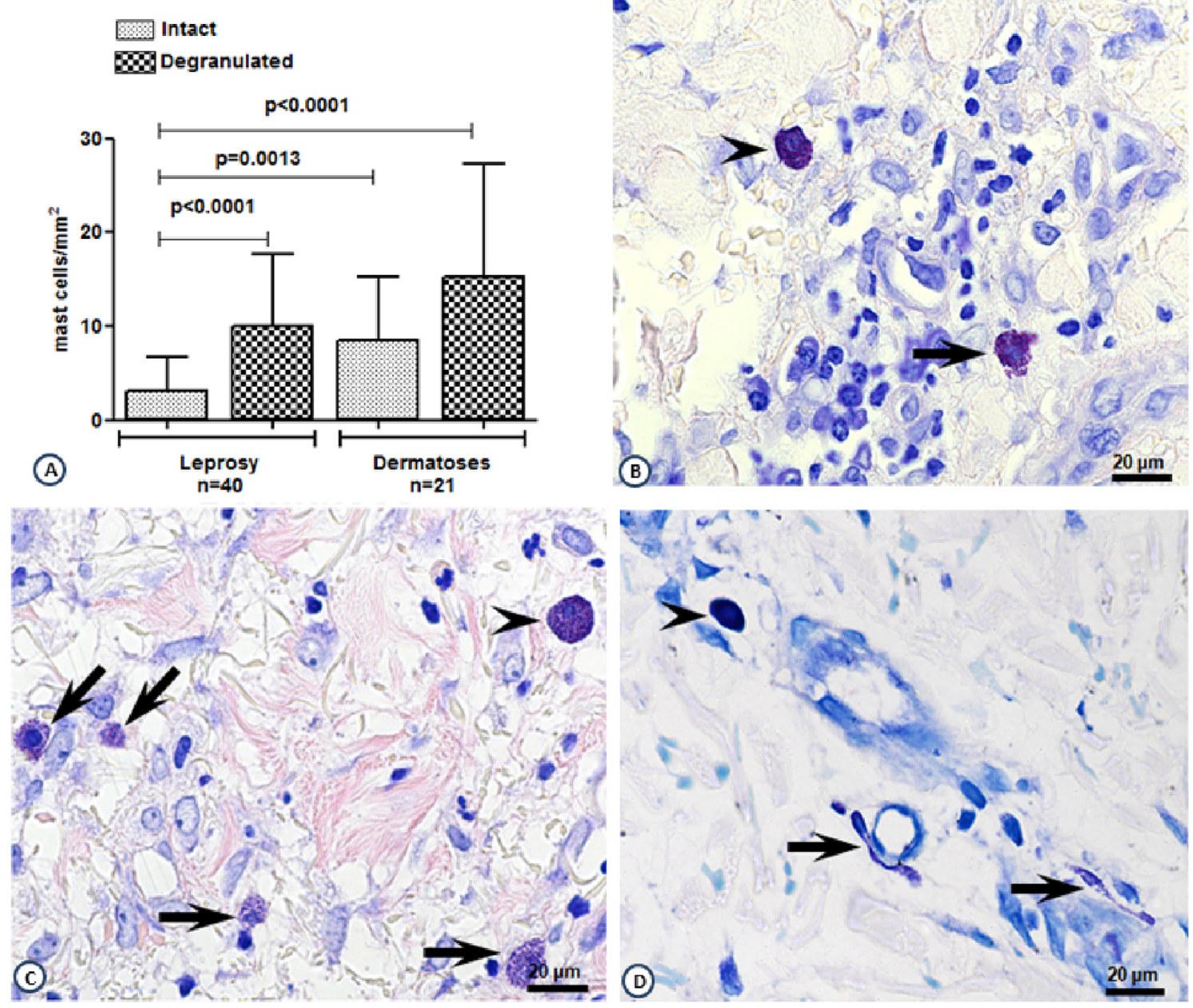

Fig. 1. (A) Quantitative analysis of intact and degranulated mast cells (MCs) in (B) leprosy lesions, (C) other dermatoses (eczema and (D) - contralateral skin biopsies). Intact MCs (arrowheads), Degranulated MCs (arrows). Stain: toluidine blue. Bars: $20 \mu \mathrm{m}$.

counterstained with Harris hematoxylin.

\subsection{Densitometry analysis}

The endogenous ANXA1 expression was analyzed (Axioskop 2-Mot Plus Zeiss microscope, Carl Zeiss, Jena, Germany), using Axio Vision software [26] and expressed as value of the mean optical density (MOD) in immunoreactive areas. The values were obtained as arbitrary units (a.u.) and reported as mean \pm S.E.M.

\subsection{Data analysis}

Exploratory data analysis, including mean, medians and standard deviation (SD) (GraphPad Prism 6 and MS Excel, 2010) was used to analyze degranulated and intact MC and try ${ }^{+}$and chy ${ }^{+}$positive MC/ $\mathrm{mm}^{2}$ among different study groups. Kruskall-Wallis one-way analysis of variance for comparison of multiple groups and Mann-Whitney for comparison between two groups assessed statistical significance; $p$ values lower than 0.05 were considered statistically significant.

\section{Ethics}

This study was approved by the regional and national review boards (Comitê de Ética em Pesquisa Humana e Animal do Hospital das Clínicas da Universidade Federal de Goiás, protocol\# 119/2005; Comissão Nacional de Ética e Pesquisa/CONEP/Brasil, protocols \# 4862, 12962). All participants signed an informed consent form.

\section{Results}

\subsection{MC heterogeneity in leprosy and other dermatoses}

Mast cells were evaluated by toluidine blue to assess metachromasia in the cytoplasmic granules (Fig. 1A-D). A significant increase of degranulated MCs compared to intact cells was observed in leprosy group ( $\mathrm{p}<0.0001$ ). A significant reduction of intact MCs in the leprosy group was observed compared to other dermatoses $(p=0.0013$ Fig. 1A).

The difference seen in the numbers of mast cells between the different groups prompted us to investigate their heterogeneity by evaluating tryptase and chymase expression (Fig. 2A-G). In leprosy lesions, the numbers of try ${ }^{+}$MCs outnumbered chy ${ }^{+} \mathrm{MC}(\mathrm{p}<0.0001)$. In other dermatoses, the numbers of try ${ }^{+}$and $\mathrm{chy}^{+}$positive cells were similar (Fig. 2A). The quantity of try ${ }^{+}$and chy ${ }^{+}$MCs was similar in all groups, whilst, the numbers of try ${ }^{+}$MCs in leprosy group outnumbered chy $^{+}$MC in other dermatoses $(\mathrm{p}=0.011)$. On the other hand, a significant increase of try $+\mathrm{MC}$ expression was observed in other dermatoses when compared with chy ${ }^{+} \mathrm{MC}$ in leprosy group $(\mathrm{p}=0.0002)$.

4.2. Mast cells in leprosy lesions: degranulation, tryptase ${ }^{+}$and $_{\text {chymase }}{ }^{+}$ subsets

Toluidine blue staining in leprosy lesions showed higher numbers of degranulated than intact MCs in TT, BT, LL leprosy forms (Fig. 3A) ( $\mathrm{p}<0.05) . \mathrm{Try}^{+} \mathrm{MC}$ outnumbered chy ${ }^{+}$MCs in all leprosy forms (TT, 

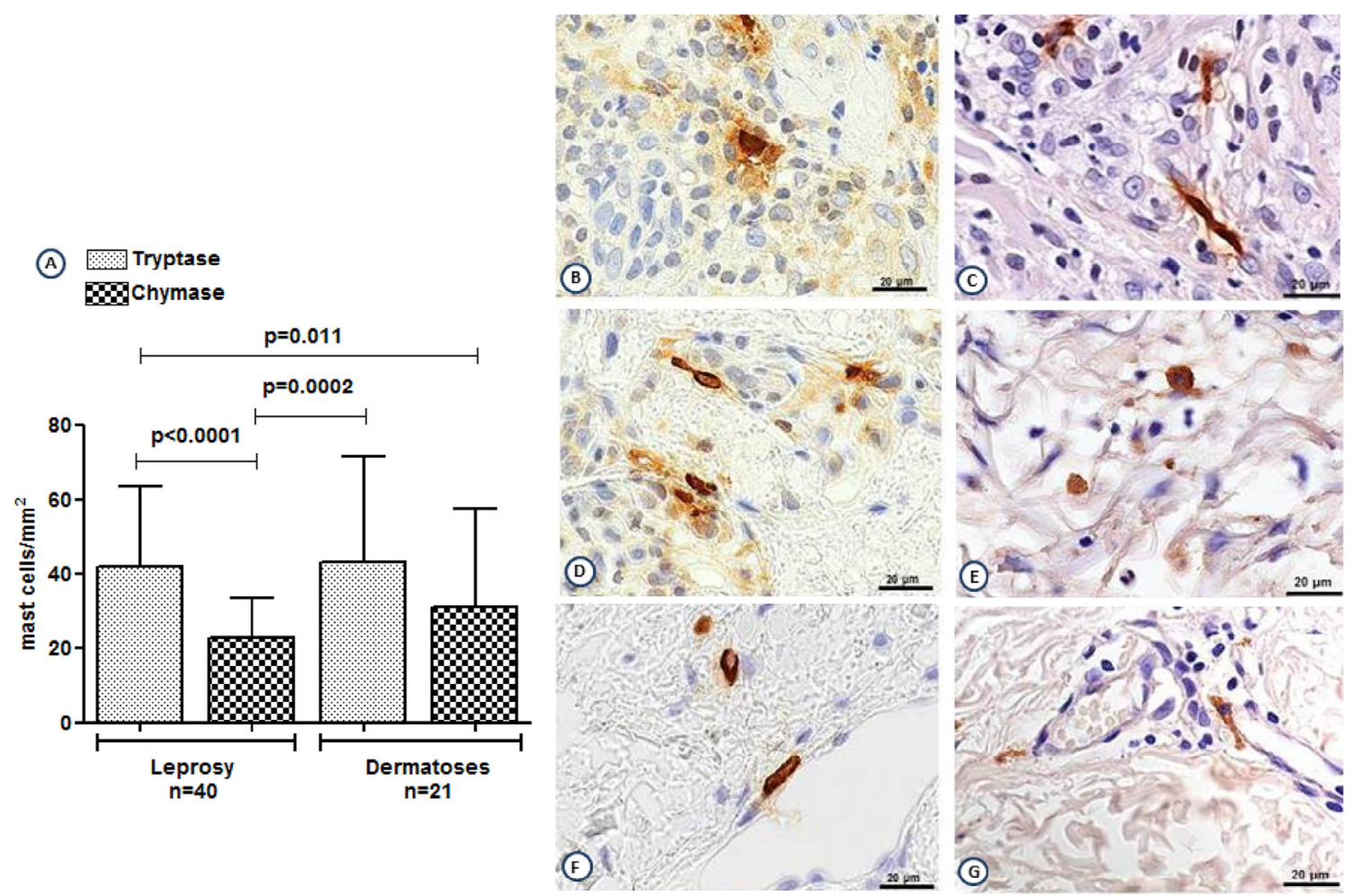

Fig. 2. Heterogeneity of the mast cells in different skin conditions. (A): Quantitative analysis of tryptase (B, D,F) and chymase (C, E,G) positive mast cells in borderline lepromatous leprosy (B, C), others dermatoses (Eczema - D, E and contralateral skin - F, G). Counterstain: Harris hematoxylin. Bars: $20 \mu \mathrm{m}$.

\section{BT, BL, LL) (p < 0.05) (Fig. 3B).}

Within reactional and reaction-free leprosy lesions (Fig. 3C) degranulated MCs outnumbered intact cells $(\mathrm{p}<0.05)$ and higher numbers of degranulated MCs were seen both in T1R and T2R lesions $(\mathrm{p}<0.050)$. Try ${ }^{+}$MCs numbers were higher than chy ${ }^{+}$MCs in reactional and reaction-free lesions $(\mathrm{p}<0.05)$ and try ${ }^{+} \mathrm{MC}$ outnumbered chy ${ }^{+} \mathrm{MC}$ in T1R and T2R ( $\mathrm{p}=0.041$ and 0.006 respectively) with more pronounced difference in T2R (Fig. 3D). Within leprosy skin lesions, intact mast cells, try ${ }^{+}$and chy ${ }^{+}$MCs were seen in epidermis, the interstice, close to blood vessels; more often inside the inflammatory infiltrates and in the periannexial region. In leprosy granulomas, MCs were identified more frequently in the lympho-histiocytic mantle than in the center of the granuloma.

4.3. Higher annexinA1 expression in leprosy skin lesions with and without reactional episode compared to other dermatoses

Because we found that leprosy lesions were associated with changing heterogeneity of MC populations, we next investigated the expression pattern of ANXA1, a potent anti-inflammatory protein that is expressed in mast cells $[38,39]$. MCs in the skin were also positive for ANXA1 (Fig. 4H), and this was confirmed by analyzing serial sections of biopsies stained with toluidine blue (Fig. 4I). Comparing other dermatoses and leprosy skin lesions, ANXA1 immunostaining evaluated by densitometry was higher in epidermis in leprosy lesions (Fig. 4A-E). The difference in ANXA1 expression between other dermatoses and leprosy skin lesions was statistically significant for all groups analyzed: MB leprosy ( $p=0.018)$, PB leprosy $(p=0.010)$, TIR $(p=0.006)$, T2R $(\mathrm{p}=0.002)$ (Fig. 4F). However, no difference in ANXA1 expression was seen in paucibacillary compared to multibacillary leprosy. Moreover, similar ANXA1 expression was seen in PB leprosy during T1R and reaction-free $\mathrm{PB}$ and in $\mathrm{MB}$ leprosy during $\mathrm{T} 2 \mathrm{R}$ lesions and in non-reactional MB leprosy (Fig. 4G). Regarding ANXA1 expression in the inflammatory foci in the dermis, high expression was seen in PB granulomas with and without T1R and also in inflammatory infiltrates of MB skin lesions both reaction-free and T2R lesions (Fig. 4A-E, G).

\section{Discussion}

Due to precedent evidence of cutaneous involvement of MCs in skin protection or pathogenesis in leprosy and other parasitic and bacterial infections [40-43], in the present study, we reported for the first time the expression of anti-inflammatory ANXA1 in leprosy lesions and MCs degranulation and heterogeneity characterized by the predominance of the tryptase positive cells.

Our investigation showed the differential expression of MCs in diverse human skin diseases. A greater amount of degranulated MCs was observed in the leprosy group independently of leprosy form, in paucibacillary and multibacillary disease regardless of the occurrence of reactions. Degranulation of MC contents implies activation and functional activity [2]. MCs can play important roles in both innate and adaptive immune responses [43], besides MCs recruit other cells such as $\mathrm{T}$ cells, neutrophils and eosinophils to the inflammatory skin site, stimulate maturation of Langerhans and dendritic cells promoting their migration to lymph nodes to activate T cells [44]. In leprosy, adaptive immunity and inflammation participate in protection and pathogenesis [45] and given the important inflammatory properties of MCs, it is expected that they may play a role in leprosy skin lesions. Although leprosy reactions are characterized by exacerbated inflammation in skin lesions and nerves [46] evidence of MCs activation by degranulation was seen in reactional and reaction-free patients, indicating that MCs degranulation are induced by $M$. leprae infection, independently of reactional episodes.

The dual nature of MC responses suggest that these inflammatory cells can alter their phenotype depending upon the prevailing immunologic context and thereby exert protective or deleterious effects $[47,48]$. Given the growing body of evidence implying mast cell proteases in different diseases [47], we decided to study MC heterogeneity in leprosy and other dermatoses according to chymase and tryptase [9] that can degrade a variety of proteins and peptides and cause 
(A)

$$
\begin{aligned}
& \text { Intact } \\
& \text { 88Degranulated }
\end{aligned}
$$

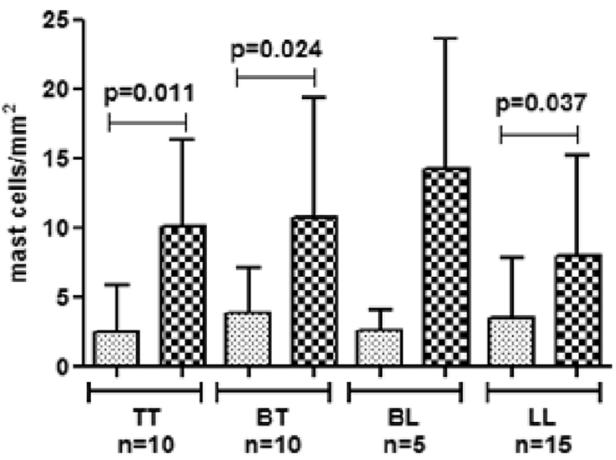

(B)
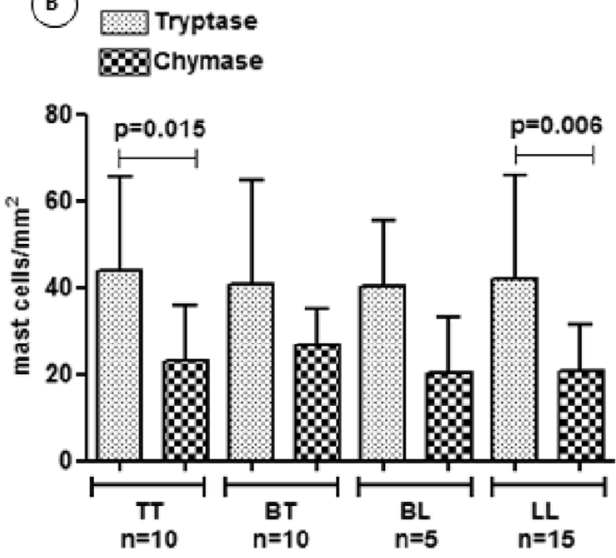

(c)

$$
\text { Intact }
$$

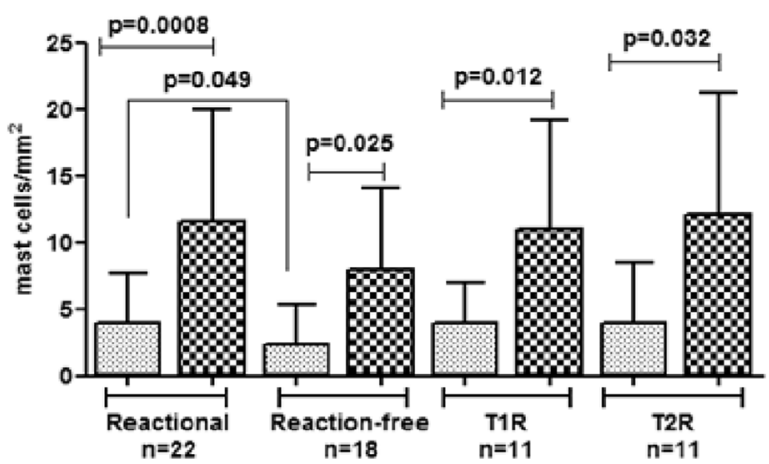

(D)

\section{Tryptase} B8chymase

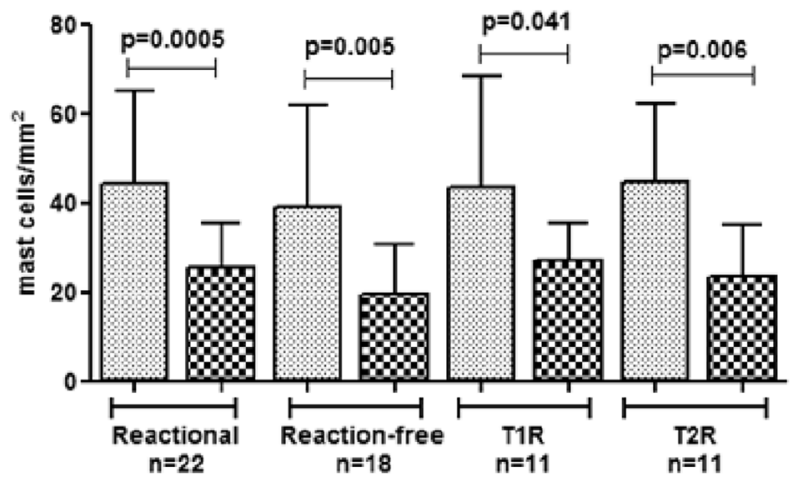

Fig. 3. (A) Toluidine blue stained intact and degranulated MCs among leprosy forms in different Ridley \& Jopling groups (TT, BT, BL and LL). (B) Immunohistochemistry analyses of tryptase and chymase positive MCs in Different leprosy forms (Ridley \& Jopling groups- TT, BT, BL and LL). (C) Toluidine blue stained intact and degranulated MCs among reactional and reaction-free leprosy patients and among T1R and T2R; (D) Tryptase and chymase positive MCs among reactional and reaction-free leprosy and among T1R and T2R.

destructive changes in the skin [49]. In our study, quantitative analysis revealed a predominance of try ${ }^{+} \mathrm{MC}$ in all leprosy forms, differently from the previously reported lower numbers of MC detected in LL leprosy [41]. Our results indicate that tryptase probably exerts function in leprosy lesions and may exert detrimental effects on tissue structure and modeling while MC derived mediators such as cytokines and chemokines can perpetuate inflammation [44]. One study on tryptase MC and nerve fibrosis showed an association of collagen increase and MC density in the epineurium [50] suggesting that MC contribute to collagenization through tryptase secretion. In our study, the numbers and the density of try ${ }^{+} \mathrm{MC}$ were elevated in T2R, which can be associated with vasculitis. Evidence from cancer biology revealed that MCs regulate angiogenesis through the production of vascular endothelial growth factor (VEGF) and release of pro-angiogenic proteases [20]. A previous study from our group searching for plasma markers of leprosy reactions by multiplex approach found a marginally significant difference for VEGF in T2R versus reaction-free controls [45]. An increase of try ${ }^{+} \mathrm{MC}$ in reactional biopsies compared to pre-reactional lesions has been previously reported [51].

In our study, the numbers of chy ${ }^{+} \mathrm{MC}$ were higher in other dermatoses compared to leprosy and activation of chy ${ }^{+} \mathrm{MC}$ has been reported in tissue fibrosis, which may be more pronounced in other dermatoses compared to leprosy [52-54]. Chymase has also been shown to contribute to the release of anti-inflammatory TGF- $\beta 1$ and it is also able to convert interleukin- $1 \beta$, a pro-inflammatory cytokine, to its active form [55] and can regulate inflammation by degrading IL- 6 and IL-13 and also TNF- $\alpha$ [56].
Despite the knowledge of mast cells as a potential "amplifiers" of chronic inflammation [57,58], inhibition of mast cell activation including the release of mediators represents a novel strategy to modulate chronic granulomatous inflammatory reactions [27,59]. Mast cells (MCs) participate in all stages of skin healing and one of their mediators is the Annexin A1 protein (AnxA1), in addition to proteases, the ANXA1 is an important mediator of mast cells [38,39,60-62]. ANXA1 is a protein linked to inflammation, proliferation, migration and apoptosis processes, which is still poorly explored in leprosy. The ANXA1 can be expressed by MC and has multiple functions in different systems, among them, membrane fusion, phagocytosis, apoptosis and proliferation [63-67]. Higher expression of ANXA1 seen in the epithelium of leprosy lesions, compared to other dermatoses, was observed in our study independently of leprosy clinical form or reactional episodes. These findings suggest that in leprosy lesions, including in T1R and T2R, ANXA1 may exert its anti-inflammatory properties, down regulating the inflammatory and adaptive immune response to prevent tissue injury and possibly nerve damage.

Previous studies have demonstrated the anti-inflammatory role of ANXA1 on adaptive immune responses, suppressing $\mathrm{T}$ cell proliferation in antigen-stimulated rat $\mathrm{T}$ cell lines, and inhibiting proliferation and activation of peripheral blood mononuclear cells from atopic individuals $[68,69]$. Absence of ANXA1 was associated with increased joint inflammation in experimental arthritis model [70], and with increased allergic inflammation in the lung in an airway hyper responsiveness model which included increased eosinophil recruitment, IL-4 production, and airway dysfunction [71]. Studies about the 

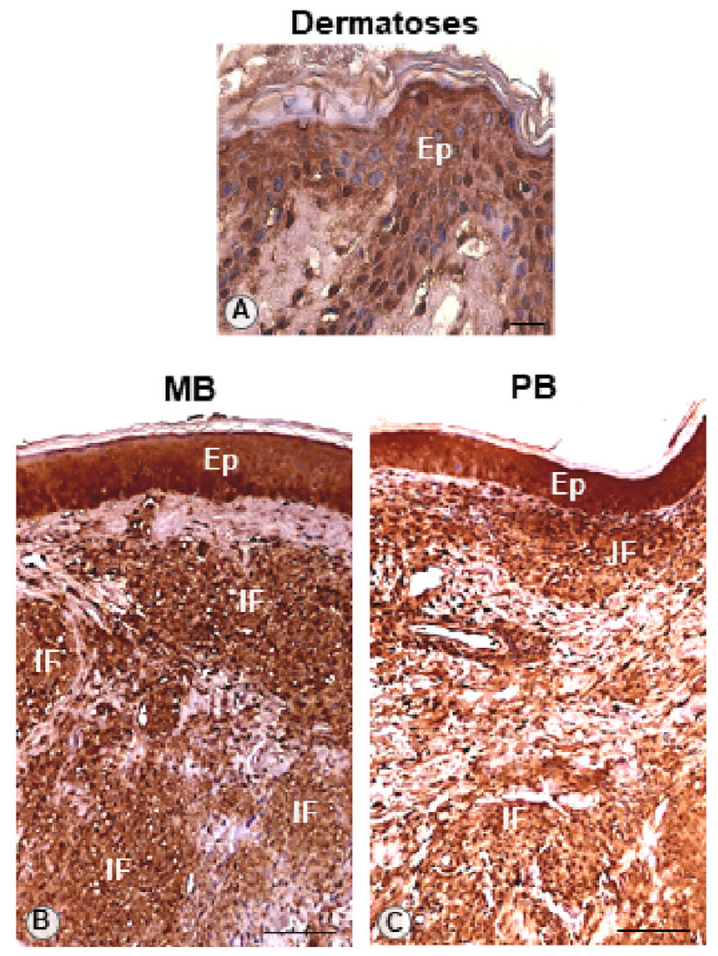

T1R

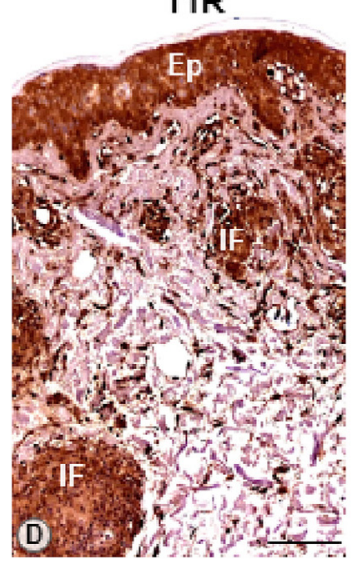

T2R

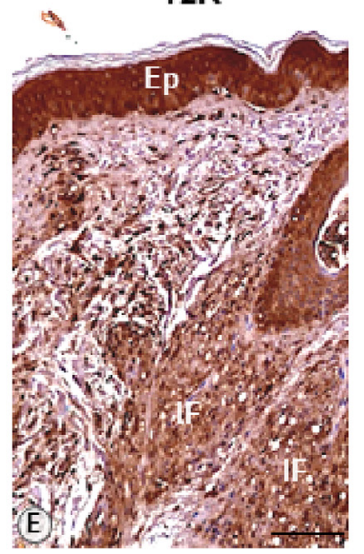

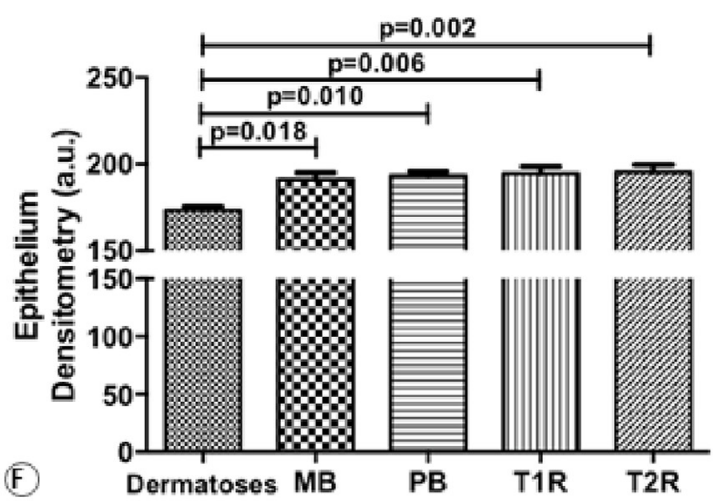

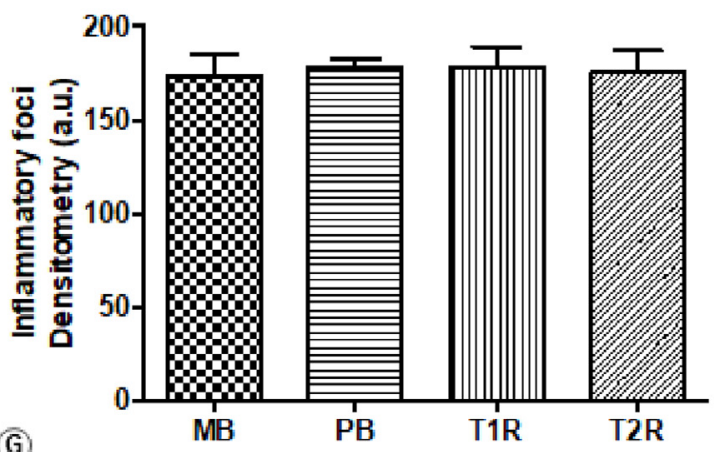

(G)

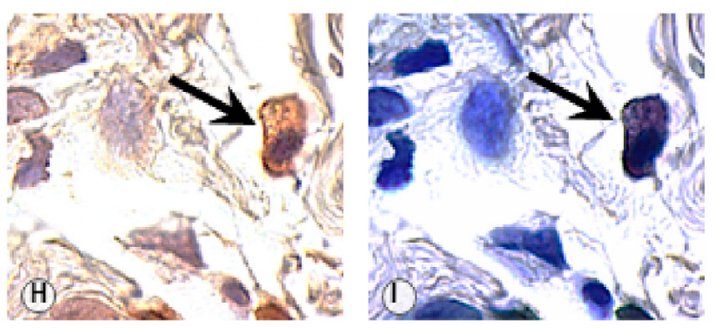

Fig. 4. Expression of ANXA1 protein in the leprosy lesion. Epidermis (Ep) and inflammatory foci (IF) were positive for ANXA1 immunostaining in other dermatoses (A), multibacillary leprosy - reaction free (B), paucibacillary leprosy - reaction free (C), paucibacillary leprosy - T1R (D) and multibacillary leprosy - reaction T2R (E) Counterstain: Harris hematoxylin. Densitometric analysis of ANXA1 expression in the (F) epidermis and (G) inflammatory foci. Data are mean - SEM of the densitometric index (arbitrary units - a.u.) of different groups. Histological section from other dermatoses positive for immunostaining (H) and stained with $0.5 \%$ toluidine blue (I) confirms that the ANXA1-positive cells are mast cell (arrow).

pathogenesis of tuberculosis showed that ANXA1 absence impairs the host adaptive immunity against Mycobaterium tuberculosis. This absence is correlated with an impaired ability of $\mathrm{ANXA1} 1^{-/-}$dendritic cells to activate naïve $\mathrm{T}$ cells and result in a transient increase in the pulmonary bacterial burden, exacerbated and disorganized granulomatous inflammation and higher susceptibility to M. tuberculosis [72]. Together these studies provide evidence that ANXA1 is able to limit inflammation and tissue damage in models associated with activation of the adaptive immune system to infectious agents, as it occurs in leprosy skin lesions, which can destroy peripheral nerves. This is the first report of a potential novel anti-inflammatory role for MC in leprosy skin lesions by expression of ANXA1, which may contribute to maintain homeostasis and to prevent tissue and nerve damage. Moreover, evidence of mast cell activation assessed by degranulation and tryptase expression triggered by the infectious process does not seem to be influenced by the leprosy form, nor the occurrence reactions.

\section{Author contributions}

MBC participated in the design of the study, carried out the histopathological analysis, immunohistochemical analysis, densitometry analysis and drafted the manuscript. AAF and EMH participated in the fieldwork, performed the statistical analysis and drafted the manuscript. ALOMS participated in the fieldwork in the diagnosis of leprosy patients. KKOM carried out the histopathological, immunohistochemical, densitometry and statistical analysis; SMO participated in the design the study, supervised immunohistochemical analysis, analyzed the data and contributed to the manuscript. MMAS conceived, designed the study, coordinated the fieldwork, analyzed the data and wrote the manuscript. All the uthors read and approved the final manuscript. 


\section{Conflicts of interest}

The authors have no conflict of interest to declare.

\section{Acknowledgments}

This work was supported by grants from gs1:Conselho Nacional de Desenvolvimento Científico e Tecnológico (grants \# 304869/2008-2 to M.M.A.S., \# 308144/2014-7 to S.M.O, \#141554/2013-4 to EMH); Fundação de Amparo à Pesquisa do Estado de São Paulo (FAPESP, Brazil, grants\# 2012/21603-2 to S.M.O., \# 2012/13041-4 to K·K.O.M.) and Coordenação de Aperfeiçoamento de Pessoal de Nível Superior (CAPES, grants\#1054292).

\section{Appendix A. Supplementary data}

Supplementary data related to this article can be found at http://dx. doi.org/10.1016/j.micpath.2018.03.050.

\section{References}

[1] S. Gudiseva, A.B.R. Santosh, R. Chitturi, V. Anumula, C. Poosarla, V.R.R. Baddam, The role of mast cells in oral squamous cell carcinoma, Wspólczesna Onkol. (2017), http://dx.doi.org/10.5114/wo.2017.65157.

[2] I.T. Harvima, G. Nilsson, Mast cells as regulators of skin inflammation and immunity, Acta Derm. Venereol. 91 (2011) 644-650, http://dx.doi.org/10.2340/ 00015555-1197.

[3] H.I.T. Lipitsä Tiina, Naukkarinen Anita, Mast cell tryptase and chymase in the progress of cutaneous vasculitis, Arch. Dermatol. Res. 307 (2015) 917-929.

[4] S.J. Galli, S. Nakae, M. Tsai, Mast cells in the development of adaptive immune responses, Nat. Immunol. 6 (2005) 135-142, http://dx.doi.org/10.1038/ni1158.

[5] M.F. Gurish, K.F. Austen, Developmental origin and functional specialization of mast cell subsets, Immunity 37 (2012) 25-33, http://dx.doi.org/10.1016/j.immuni. 2012.07.003.

[6] T.A. Wilgus, B.C. Wulff, The importance of mast cells in dermal scarring, Adv. Wound Care 3 (2014) 356-365, http://dx.doi.org/10.1089/wound.2013.0457.

[7] J. Douaiher, J. Succar, L. Lancerotto, M.F. Gurish, D.P. Orgill, M.J. Hamilton, S.A. Krilis, R.L. Stevens, Development of mast cells and importance of their tryptase and chymase serine proteases in inflammation and wound healing, Adv. Immunol. 122 (2014) 211-252, http://dx.doi.org/10.1016/B978-0-12-800267-4.00006-7.

[8] L.B. Schwartz, A.M. Irani, Mast cell heterogeneity, Clin. Exp. Allergy 19 (1989) 143-145.

[9] N. Weidner, K.F. Austen, Heterogeneity of mast cells at multiple body sites. Fluorescent determination of avidin binding and immunofluorescent determination of chymase, tryptase, and carboxypeptidase content, Pathol. Res. Pract. 189 (1993) $156-162$.

[10] N.-C. Diaconu, R. Kaminska, A. Naukkarinen, R.J. Harvima, I.T. Harvima, The in crease in tryptase- and chymase-positive mast cells is associated with partial inactivation of chymase and increase in protease inhibitors in basal cell carcinoma, $\mathrm{J}$. Eur. Acad. Dermatol. Venereol. 21 (2007) 908-915, http://dx.doi.org/10.1111/j. 1468-3083.2006.02100.x.

[11] T.C. Moon, A.D. Befus, M. Kulka, Mast cell mediators: their differential release and the secretory pathways involved, Front. Immunol. 5 (2014) 569, http://dx.doi.org/ 10.3389/fimmu.2014.00569.

[12] R.E. Sutherland, J.S. Olsen, A. McKinstry, S.A. Villalta, P.J. Wolters, Mast cell IL-6 improves survival from Klebsiella Pneumonia and sepsis by enhancing neutrophil killing, J. Immunol. 181 (2008) 5598-5605 doi:181/8/5598 [pii].

[13] N.M. Michels, H.W. Chu, S.C. Lafasto, S.R. Case, M.N. Minor, R.J. Martin, Mast cells protect against airway Mycoplasma pneumoniae under allergic conditions, Clin. Exp. Allergy (2010) 1-8, http://dx.doi.org/10.1111/j.1365-2222.2010.03488.x.

[14] C.J.W.R.A.W.M.W. Tanaka RD, Mast cell tryptase: a new target for therapeutic intervention in asthma, Int. Arch. Allergy Immunol. 107 (1995) 408-409.

[15] M. Juremalm, G. Nilsson, Chemokine receptor expression by mast cells, Chem. Immunol. Allergy 87 (2005) 130-144 doi:87640 [pii] \n10.1159/000087640.

[16] W. Dawicki, J.S. Marshall, New and emerging roles for mast cells in host defence, Curr. Opin. Immunol. 19 (2007) 31-38, http://dx.doi.org/10.1016/j.coi.2006.11. 006.

[17] B.A. Sayed, M.A. Brown, Mast cells as modulators of T-cell responses, Immunol. Rev. 217 (2007) 53-64, http://dx.doi.org/10.1111/j.1600-065X.2007.00524.x.

[18] D. Skokos, H.G. Botros, C. Demeure, J. Morin, R. Peronet, G. Birkenmeier, S. Boudaly, S. Mécheri, Mast cell-derived exosomes induce phenotypic and functional maturation of dendritic cells and elicit specific immune responses in vivo, J. Immunol. 170 (2003) 3037-3045.

[19] J. Cao, W. Boucher, D. Kempuraj, J.M. Donelan, T.C. Theoharides, Acute stress and intravesical corticotropin-releasing hormone induces mast cell dependent vascular endothelial growth factor release from mouse bladder explants, J. Urol. 176 (2006) 1208-1213, http://dx.doi.org/10.1016/j.juro.2006.04.026.

[20] S.M. Oliani, M.J. Paul-Clark, H.C. Christian, R.J. Flower, M. Perretti, Neutrophil interaction with inflamed postcapillary venule endothelium alters annexin 1 expression, Am. J. Pathol. 158 (2001) 603-615, http://dx.doi.org/10.1016/S00029440(10)64002-3.

[21] S. Ernst, C. Lange, A. Wilbers, V. Goebeler, V. Gerke, U. Rescher, An annexin 1 Nterminal peptide activates leukocytes by triggering different members of the formyl peptide receptor family, J. Immunol. 172 (2004) 7669-7676 doi:172/12/7669 [pii].

[22] S.L. Williams, I.R. Milne, C.J. Bagley, J.R. Gamble, M.A. Vadas, S.M. Pitson, Y. Khew-Goodall, A proinflammatory role for proteolytically cleaved annexin A1 in neutrophil transendothelial migration, J. Immunol. 185 (2010) 3057-3063, http:// dx.doi.org/10.4049/jimmunol.1000119.

[23] K.K. Mimura, R.C. Tedesco, K.S. Calabrese, C.D. Gil, S.M. Oliani, The involvement of anti-inflammatory protein, annexin A1, in ocular toxoplasmosis, Mol. Vis. 18 (2012) 1583-1593.

[24] A.P. Girol, K.K.O. Mimura, C.C. Drewes, S.M. Bolonheis, E. Solito, S.H.P. Farsky, C.D. Gil, S.M. Oliani, Anti-inflammatory mechanisms of the annexin A1 protein and its mimetic peptide Ac2-26 in models of ocular inflammation in vivo and in vitro, J. Immunol. 190 (2013) 5689-5701, http://dx.doi.org/10.4049/jimmunol.1202030.

[25] F.N.E. Gavins, M.J. Hickey, Annexin A1 and the regulation of innate and adaptive immunity, Front. Immunol. 3 (2012) 354, http://dx.doi.org/10.3389/fimmu.2012 00354.

[26] R.B. Molás, M. de Paula-Silva, R. Masood, A. Ullah, A.D. Gimenes, S.M. Oliani, Ac226 peptide and serine protease of Bothrops atrox similarly induces angiogenesis without triggering local and systemic inflammation in a murine model of dorsa skinfold chamber, Toxicon (2017), http://dx.doi.org/10.1016/j.toxicon.2017.06. 009.

[27] S.M. Oliani, G.A.P. Ciocca, T.A. Pimentel, A.S. Damazo, L. Gibbs, M. Perretti, Fluctuation of annexin-A1 positive mast cells in chronic granulomatous inflammation, Inflamm. Res. 57 (2008) 450-456, http://dx.doi.org/10.1007/s00011008-7222-7.

[28] Y. Gao, Y. Chen, D. Xu, J. Wang, G. Yu, Differential expression of ANXA1 in benign human gastrointestinal tissues and cancers, BMC Canc. 14 (2014) 520, http://dx. doi.org/10.1186/1471-2407-14-520.

[29] WHO, Weekly Epidemiological record Relevé épidémiologique hebdomadaire vol. III, (2014), pp. 389-400.

[30] D.M. Scollard, L.B. Adams, T.P. Gillis, J.L. Krahenbuhl, R.W. Truman, D.L. Williams, The continuing challenges of leprosy, Clin. Microbiol. Rev. 19 (2006) 338-381, http://dx.doi.org/10.1128/CMR.19.2.338.

[31] H.M. Van Hale, S.B. Turkel, T.H. Rea, Dermal ultrastructure in leprosy, Arch. Pathol. Lab Med. 108 (1984) 383-386.

[32] S.D. Rav, V.K. Pratap, N.K. Sharma, S.S. Dayal, Mast cell in leprosy, Indian J. Lepr. 62 (1990) 467-472.

[33] K. Aroni, G. Kontochristopoulos, A. Liossi, D. Panteleos, An investigation of mast cells in two basic leprosy groups, Int. J. Lepr. Other Mycobact. Dis. 61 (1993) 634-635.

[34] V.V. Mysorekar, C.P. Dandekar, S.G. Rao, Mast cells in leprosy skin lesions, Lepr. Rev. 72 (2001) 29-34.

[35] I.N. Bagwan, M.M. Khandekar, P. Kadam, M.V. Jadhav, S.D. Deshmukh, A study of mast cells in granulomatous lesions of skin, with special emphasis on leprosy, Indian J. Lepr. 76 (2004) 31-37.

[36] D.S. Ridley, W.H. Jopling, Classification of leprosy according to immunity. A fivegroup system, Int. J. Lepr. Other Mycobact. Dis. 34 (1966) 255-273.

[37] T.A. Pimentel, A.L.F. Sampaio, F. D'Acquisto, M. Perretti, S.M. Oliani, An essentia role for mast cells as modulators of neutrophils influx in collagen-induced arthritis in the mouse, Lab. Invest. 91 (2011) 33-42, http://dx.doi.org/10.1038/labinvest. 2010.140 .

[38] S.M. Oliani, H.C. Christian, J. Manston, R.J. Flower, M. Perretti, An immunocytochemical and in situ hybridization analysis of annexin 1 expression in rat mast cells: modulation by inflammation and dexamethasone, Lab. Invest. 80 (2000) $1429-1438$.

[39] A.C. Polli-Lopes, C.F. Estofolete, S.M. Oliani, S. Zucoloto, F.Q. Cunha, C.D. Gil, Myenteric denervation in gastric carcinogenesis: differential modulation of nitric oxide and annexin-A1, Int. J. Clin. Exp. Pathol. 6 (2013) 13-23.

[40] F. Siebenhaar, W. Syska, K. Weller, M. Magerl, T. Zuberbier, M. Metz, M. Maurer, Control of Pseudomonas aeruginosa skin infections in mice is mast cell-dependent, Am. J. Pathol. 170 (2007) 1910-1916.

[41] G.O. Magalhaes, V.C. Valentim, M.J. Pereira, J.A. Nery, X. Illarramendi, S.L. Antunes, A quantitative and morphometric study of tryptase-positive mast cell in cutaneous leprosy lesions, Acta Trop. 105 (2008) 62-66, http://dx.doi.org/10. 1016/j.actatropica.2007.10.001.

[42] M. Metz, F. Siebenhaar, M. Maurer, Mast cell functions in the innate skin immune system, Immunobiology 213 (2008) 251-260, http://dx.doi.org/10.1016/j.imbio. 2007.10.017.

[43] S. Igawa, A. Di Nardo, Skin microbiome and mast cells, Transl. Res. (2017), http:// dx.doi.org/10.1016/j.trsl.2017.03.003.

[44] S. Bulfone-Paus, R. Bahri, Mast cells as regulators of T Cell responses, Front. Immunol. (2015), http://dx.doi.org/10.3389/fimmu.2015.00394.

[45] M.M. Stefani, J.G. Guerra, A.L.M. Sousa, M.B. Costa, M.L.W. Oliveira, C.T. Martelli, D.M. Scollard, Potential plasma markers of Type 1 and Type 2 leprosy reactions: a preliminary report, BMC Infect. Dis. 9 (2009) 75.

[46] I. Nath, C. Saini, V.L. Valluri, Immunology of leprosy and diagnostic challenges, Clin. Dermatol. 33 (2015) 90-98, http://dx.doi.org/10.1016/j.clindermatol.2014. 07.005.

[47] H. Dai, R.J. Korthuis, Mast cell proteases and inflammation, Drug Discov. Today Dis. Model. 8 (2011) 47-55, http://dx.doi.org/10.1016/j.ddmod.2011.06.004.

[48] G.H. Caughey, Mast cell proteases as pharmacological targets, Eur. J. Pharmacol. (2015), http: $/ 7 \mathrm{x}$. 
[49] A. Yadav, R.S. Desai, B.A. Bhuta, J.S. Singh, R. Mehta, A.P. Nehete, Altered Immunohistochemical expression of mast cell tryptase and chymase in the pathogenesis of oral submucous fibrosis and malignant transformation of the overlying epithelium, PLoS One 9 (2014), http://dx.doi.org/10.1371/journal.pone.0098719.

[50] N.A. Montagna, M.L. de Oliveira, C.A. Mandarim-de-Lacerda, L. Chimelli, Leprosy: contribution of mast cells to epineurial collagenization, Clin. Neuropathol. 24 (2005) 284-290 yes.

[51] S.L.G. Antunes, Y. Liang, J.A. da, C. Neri, E.N. Sarno, M. Haak-Frendscho, O. Johansson, Mast cell subsets and neuropeptides in leprosy reactions, Arq. Neuro. Psiquiatr. 61 (2003) 208-219, http://dx.doi.org/10.1590/S0004282X2003000200010.

[52] Y. Tomimori, T. Muto, K. Saito, T. Tanaka, H. Maruoka, M. Sumida, H. Fukami, Y. Fukuda, Involvement of mast cell chymase in bleomycin-induced pulmonary fibrosis in mice, Eur. J. Pharmacol. 478 (2003) 179-185, http://dx.doi.org/10.1016/ j.ejphar.2003.08.050.

[53] A. Akgul, Can cardiac fibrosis be prevented? Mast cell inhibition versus anti-chymase activity, Eur. J. Cardio. Thorac. Surg. 35 (2009) 553-554.

[54] Y.-D. Lang, S.-F. Chang, L.-F. Wang, C.-M. Chen, Chymase mediates paraquat-induced collagen production in human lung fibroblasts, Toxicol. Lett. 193 (2010) $19-25$.

[55] X. Dong, J. Chen, Y. Zhang, Y. Cen, Mast cell chymase promotes cell proliferation and expression of certain cytokines in a dose-dependent manner, Mol. Med. Rep. 5 (2012) 1487-1490, http://dx.doi.org/10.3892/mmr.2012.851.

[56] S. Nelissen, T. Vangansewinkel, N. Geurts, L. Geboes, E. Lemmens, P.M. Vidal, S. Lemmens, L. Willems, F. Boato, D. Dooley, D. Pehl, G. Pejler, M. Maurer, M. Metz, S. Hendrix, Mast cells protect from post-traumatic spinal cord damage in mice by degrading inflammation-associated cytokines via mouse mast cell protease 4 Neurobiol. Dis. 62 (2014) 260-272.

[57] M. Metz, M.A. Grimbaldeston, S. Nakae, A.M. Piliponsky, M. Tsai, S.J. Galli, Mast cells in the promotion and limitation of chronic inflammation, Immunol. Rev. 217 (2007) 304-328, http://dx.doi.org/10.1111/j.1600-065X.2007.00520.x.

[58] M. Ferrer, Immunological events in chronic spontaneous urticaria, Clin. Transl. Allergy (2015), http://dx.doi.org/10.1186/s13601-015-0074-7.

[59] A. Russo, G. Russo, M. Peticca, C. Pietropaolo, M. Di Rosa, T. Iuvone, Inhibition of granuloma-associated angiogenesis by controlling mast cell mediator release: role of mast cell protease-5, Br. J. Pharmacol. 145 (2005) 24-33, http://dx.doi.org/10. 1038/sj.bjp.0706112.

[60] C.D. Gil, M. La, M. Perretti, S.M. Oliani, Interaction of human neutrophils with endothelial cells regulates the expression of endogenous proteins annexin 1, galectin-1 and galectin-3, Cell Biol. Int. 30 (2006) 338-344, http://dx.doi.org/10. 1016/j.cellbi.2005.12.010.

[61] R. Paula, A.H. Oliani, D.C.M. Vaz-Oliani, S.C.G.P. D’Ávila, S.M. Oliani, C.D. Gil, The intricate role of mast cell proteases and the annexin A1-FPR1 system in abdominal wall endometriosis, J. Mol. Histol. 46 (2015) 33-43 http://www.ncbi.nlm.nih.gov/ pubmed/25201101.

[62] H.R. Souza, L.R. De Azevedo, L. Possebon, S. De Souza Costa, M.M. Iyomasa-Pilon, S.M. Oliani, A.P. Girol, Heterogeneity of mast cells and expression of Annexin A1 protein in a second degree burn model with silver sulfadiazine treatment, PLoS One (2017), http://dx.doi.org/10.1371/journal.pone.0173417.

[63] R.J. Flower, N.J. Rothwell, Lipocortin-1: cellular mechanisms and clinical relevance, Trends Pharmacol. Sci. 15 (1994) 71-76.

[64] M. Perretti, R.J. Flower, Annexin 1 and the biology of the neutrophil, J. Leukoc. Biol. 76 (2004) 25-29, http://dx.doi.org/10.1189/jlb.1103552.

[65] A.M. Kamal, R.J. Flower, M. Perretti, An overview of the effects of annexin 1 on cells involved in the inflammatory process, Mem. Inst. Oswaldo Cruz 100 (2005) 39-48, http://dx.doi.org/10.1590/S0074-02762005000900008.

[66] F. D'Acquisto, M. Perretti, R.J. Flower, Annexin-A1: a pivotal regulator of the innate and adaptive immune systems, Br. J. Pharmacol. 155 (2008) 152-169, http://dx. doi.org/10.1038/bjp.2008.252.

[67] S. Yazid, A. Sinniah, E. Solito, V. Calder, R.J. Flower, Anti-Allergic cromones inhibit histamine and eicosanoid release from activated human and murine mast cells by releasing annexin A1, PLoS One 8 (2013), http://dx.doi.org/10.1371/journal.pone. 0058963 e58963.

[68] R. Gold, R.B. Pepinsky, U.K. Zettl, K.V. Toyka, H.P. Hartung, Lipocortin-1 (annexin1) suppresses activation of autoimmune $T$ cell lines in the Lewis rat, $J$. Neuroimmunol. 69 (1996) 157-164.

[69] A.M. Kamal, S.F. Smith, M. De Silva Wijayasinghe, E. Solito, C.J. Corrigan, An annexin 1 (ANXA1)-derived peptide inhibits prototype antigen-driven human T cell Th1 and Th2 responses in vitro, Clin. Exp. Allergy 31 (2001) 1116-1125 http:// www.ncbi.nlm.nih.gov/pubmed/11468004.

[70] H.B. Patel, K.N. Kornerup, A.L. Sampaio, F. D'Acquisto, M.P. Seed, A.P. Girol, M. Gray, C. Pitzalis, S.M. Oliani, M. Perretti, The impact of endogenous annexin A1 on glucocorticoid control of inflammatory arthritis, Ann. Rheum. Dis. 71 (2012) 1872-1880, http://dx.doi.org/10.1136/annrheumdis-2011-201180.

[71] F.S. Ng, K.Y. Wong, S.P. Guan, F.B. Mustafa, T.S. Kajiji, P. Bist, S.K. Biswas, W.S. Wong, L.H. Lim, Annexin-1-deficient mice exhibit spontaneous airway hyperresponsiveness and exacerbated allergen-specific antibody responses in a mouse model of asthma, Clin. Exp. Allergy 41 (2011) 1793-1803, http://dx.doi.org/10. 1111/j.1365-2222.2011.03855.x.

[72] K.H.Q. Vanessa, M.G. Julia, L. Wenwei, A.L.T. Michelle, Z.R.S. Zarina, L.H.K. Lina, A. Sylvie, Absence of Annexin A1 impairs host adaptive immunity against Mycobacterium tuberculosis in vivo, Immunobiology 220 (2015) 614-623, http:// dx.doi.org/10.1016/j.imbio.2014.12.001. 